\title{
Espectrometria de Massa de Electrospray - Técnica do Presente e do Futuro
}

\author{
M.F.DUARTE*
}

\section{INTRODUC $\ddot{A} O$}

A espectronctria de massa é uma Iécrica analítica poderosa yuc é usada para identificar compostos desconhecidos, quanificar materiais conlecidos e elucidar as propriedades químicas e estruuurais das moléculas. A delecção de composios pode ser conseguida para quamaidades tāo pequenas como $10.15 \mathrm{~g}$ para um composio de massa de 1000 Dalton. Isto signilica que os compostos podem str identificados en concentraçōes muito baixas I uma parte em $10^{12}$ ) em misturas quimicanente compluxas. A especirometria de massa fornece informaçāo tanto para quínicos, como para físicos, engenheirus de controlo de processos. bioquimicos e ainda biologistas. mara só citar alguns.

Os princípios cientílicos :mon que a técnica se baseia sāo simples. $A$ essência da lécnica envolse a geraçă de iōes ytu sãu depois delcciados. A sofisticaçăo surge nos múrodos que sẽo usados para a geraçu desses mesmos lōes e no modo de os analisar.

Uma das lécnicas de ionizaçăo. em maior expansão, é por elecırospray quic passou por duas fases distintas de investigaca c desenvolvimento. A primeirä decorrutu antes de 1970 e centrou-se mais nos aspectos lundamentais do processo de produçào de carga assim como IIo modo experimumtal de o concretizar, sendo de salictitar o trabalho rualizado por Dole et al.], [. A segutha fase deu-se a parrir de 1970 con theslaque para o Irabalito desenvolvido em 1984 por Yamashita e Fenn [2]. considerado pioneiro da espectronetria de massa de ionização por elecrrospray. A partir deste trabalho a ićcrica solreu um incremento notório colus o desenvolvimente co construçāo de fontes iónicas comercializáveis baseadas no principio de carrcgar golas electricamenle.

llá essencialmente três caracterișticas que lazcm com que seja considerada uma técnica distina das otiIras lécnicas de ionizaçăo. A primeira destas caracteristicas ć a capacidade para produzir jóes multiplamente carregados, com númlera de cargas elevado, reduzindo, asșing a razão m/z, de tal modo yue seja possive! analisar compostos de elevada massa molecular aic centenas de kDa. em praticamena todo o lino de analisa dores. Unma segunda caracteristica yuce as amostras a analisar devent ser introduzidas t'mı suluçăo. o yuc [az. cum que seja pussivel o acoplanuento com muitas técnicas de separacäo. Por último c nãu menos impurlante 1) facto de ser o electrospray uma técnica de ionizaçāo suave permilindo yue as interaçñes rão covaltutes entre moléculas yue existem em soluça sejam preservadas na fase ga. sosa.

0 desenvolvimento da esjectrometria de massa de ionizaçāo por electuspray nermiliu assim novas possibilidades para análise de compustos de elevada massa molecular de lodos os tipos, incluindo protejnas. nucleotidos e polímeros sintéticos, sendo por isso uma técnica muito usada em investigaça biolúpica, bioy.uimica, larmacétutica e médica.

\section{MECANISMO}

A produçău de iōes en electros pray requer esstucialmente dois passos: dispersāo dì gotas altamcinc carrcgadas quase à prcssāo atijuosté rica seguida de condiçócs qute permitaij) a ['vaporaça da gota.

As solucōes são primeiratjuente pulverizadas electrostaticamentu com formaçāo de gotas pequenas e alıamente carregadas. A nebulizaçāo da solução t nalguns casos [acilitada pela ajuda de um gás nebulizador. Pusteriormetic as moléculas to andlito devem te alguma lorma ser separadas do solvente na forma de iŏts. Este passo de formaçāo de iōes como em muilas das técnicas de ionização consideradas suaves é prova velmence o remos comprecondide no processo glubal to electrospray. Alpuns mecanismus tếm sido proposios para a desadsurçāo de iōes a partir do gotas carregatas sendo que o modelo de residuo de corga de Dole [1]. aplica- do a macromoléculas. foi ralvezo primeiro a servir de base para a actual técnica de electrospray. Neste modelo éc considerado qut à medida qu o solvente se evapora a densidade de cargà à superficic a umentará atć que as forças repulsivas da Coulomb entre as cargas superficiais excederäo a tensāo superficial levando à diviș̄o da guta inicial. Se uste processu du đivisùo continuar e se a solução original for suficientemence dil uída strá alcancado um estado no qual cada gota conlerá mrna única nuolécula que relerá parte da carga inicial, ou seja formar-se-ão macro iōes.

Um outo mecanismo, para a geraşào de iốs pequenos, o da eva peraçu timia foi proposio, por J ribarne e Thomson [3]. que sugerem que a evaporaçāo do solvtnle conduz a uma intstabilidade das gotas com razóes elevadas de densidade de carga superficial/ raio da gota. A energia elcctrostálica associada cum a gota carregada torna-se enเaีo suficiente menle granda para desadsurver iôes do analito para a fase gasosa. Un esquema da sequência dos acontcoi mentus que conduzem à formaçăo de iöes pode ser visto na Fig. 1

Este mecanismo foi aplicado a macromoléculas por Fenm [5] o ugua] propôs utuc uma parte da molécula carregada, nodia pencurar a superícje da gota devido a movimentu Brorvniano. A existência dé repulsăı conlonibiana entre esta parce da molécula e a superfícic da gola puxará a molécula para fura da gúa.

\section{INSTRUMENTAÇ̃̃O}

\subsection{Fonte}

As [untes iónicas dos esperaró metros de massa estāo en geral situa. das numa região de alto vácuo. No caso da fonte de ionização por electrospray ela encontra-se à pressão almos[érica e a evaporaçăo do solvente é muitas vezes completada por intermédio de um fluxo comtra corrente de um gás, ent geral, a7olo. Os iōes gerados são depois Iransferidos desla zona de alla pressäo para a zona dc alto vácuo do analisador de massa. 


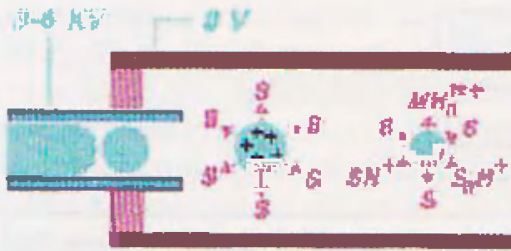

EVAPORAGÄO IONICA

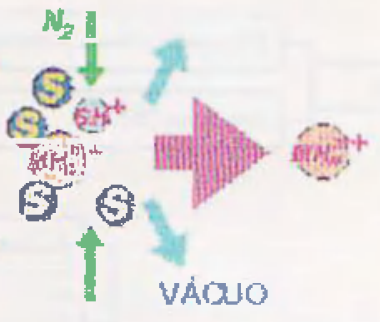

FDREAS REPULSORAS COULOMBIANAS Eे

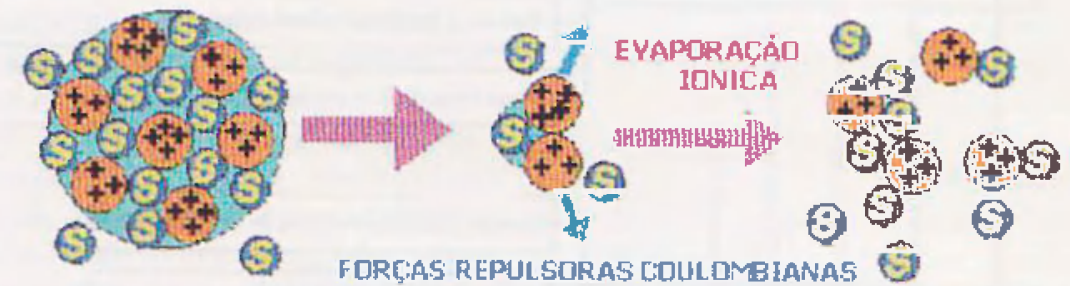

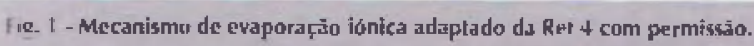

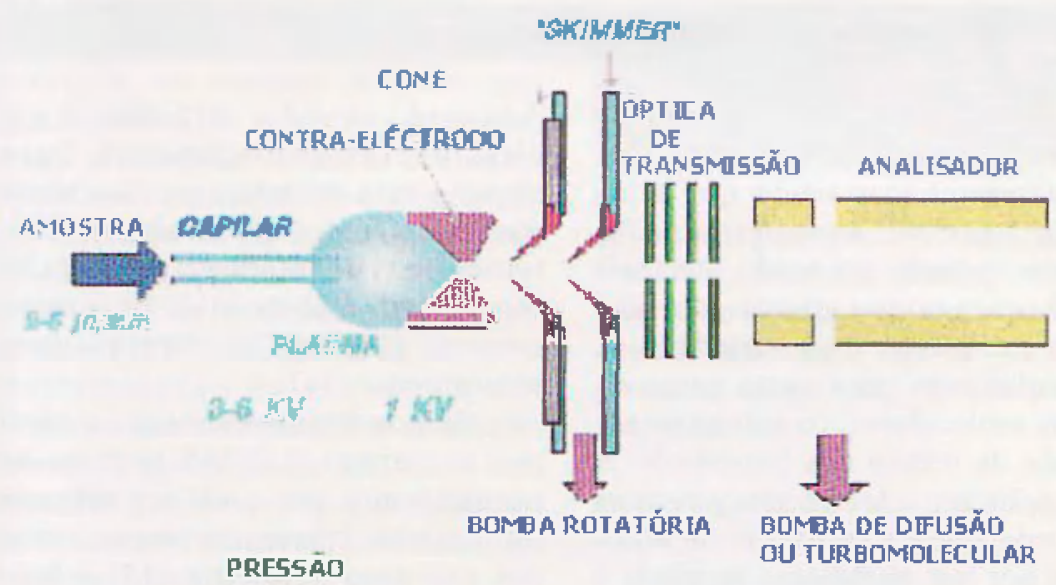

ATMOSFERICA

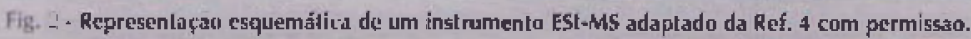

Muitos sảo os sistemas de elec. trospray que tem sido construídos [6.7], diferindo entre si nalguns dos componentes, mas na sua essência sāu constituídos por:

- sistema de iniroduçäo de amostra

- regiāo da fonte onde os iōes sāo gerados de iōes

- um orifício para amostragem

- un sistuma de transferência innica onde us iōes são transportados para o analísador de massa.
Na Fig. 2 podemos ver as principais caracteristicas de um sistema de electrospray,

Em primeiro lugar temos um capiiar du aço inoxidăvel, mantido a um potencial relativamente elevado em relação a um contra-eléctrodo. onde $v$ analito em soluçāo é int roduzido e pulverizado na sua extremidade, sendo que o sinal do potencial aplicado determina a polaridade das gotas e dos jồes formados. A pressāo entre o capilar e o contra- elécirodo é a pressăo atmosférica, sendo em seguida os iōes amustrados através de um cone un orifício passando os jōes a uma zona inzormédia mantida a uma pressão mais baixa por meio de uma bomba rotatória. Os iōes alravessam em suguida un skimmer em direç̧āo ao analisador que se encontra a alto vácuo. O skimmer funciona como um separador de momento sendo que os ines amostra mats pesados passam através delc enquanto que as moléculas mais leves de gás e solvente sāo bombeadas.

\subsection{Analisador}

O analisador mais utilizado e mesmo o primciro a ser comerciali. 7ado um ESMS é o quadrupolo. Isto deve-se em princípio ao lacto de os quadrupolos screm relativamente baratos, fáceis de usar e capazes de furnecer bom rigor nos valores de massa medidos. No entanto a resolũ̧̧o é limitada e a transmissão diminui linearmente com $\mathrm{m} / \mathrm{z}$ sendo o limite superior de m/z cerca de 3000 . Analisadores de sector podem fornecer melhor rigor. maior resuluçào a mesmo maior sensibilidade que os quadrupolos. cm instrumentos que dispōem de um delector de array [8]. A combinaçăo de ES a instrumentos de sector de dupla focagem foi concretizada $[9.10]$ apesar desta combinaçāo ser problemática devido à necessidade de utilizaçăo de potenciais eléctricos da ordem dos $\mathrm{kV}$ para acclèJaçào dos iồes. a existência dos quais pode provocar descargas eléctricas na zona de pressāo intermédia. Em consequẻncia, neste tipo de assoçaçăo de analisador de sector a fontes Iuncionando à pressāo almosférica, luă necessidade dé sistemas de hombcamento adicionais para que haja um decréscimo de pressāo mais gradual.

Outro tipo de analisadores tém sido usados cm combinação com electrospray sempre com o intuito de melhorar quer a resolução, quer o rigor na medida quer a sensibilidade. Entre eles são de salientar o de ressonância ciclotrónica de iôes con transformadas de Fourier. FTICR, [11,12] e o de tempo de vôo. TOF. [13]. O primeiro E um instrumento 
capaz de lomecer elevado poder de resolução e etevada sensibilidade benu como medida de massa rigorosa e na verdade a combinaçăo de ESI com ETICR está a sornar-se numa las técnicas mais poderosas para análise estrutural de grandes biomoléculas. Esta combinação apresentou alé rectentemente muias diliculdades experimcutais, basicamente, por causa da prussāo muito baixa. 10-6 a $10 \cdot 7 \mathrm{~Pa}$, necessária para se obter as melhores condtiçes de Iuncionamento do instrumemo. Presentemelle os especrómetros ESI/FTlCR dispōm de 3 a 5 estágios de hombeamenlu diferencial para conseguir a redução de pressảo desejada, Quanto ao segundn, o TOF, existia o problema do acoplanenlo de uma fonte cominua como a de electruspray a um instrumento pulsado como o TOF sem haver perda de sensibiłidade. o que foi conseguido com a chamada injeção jónica ortogonal. assim como foi conseguida uma elevada resoluçăo com o uso de reflectores elecurosláticos [14].

\section{ELECTROSPRAY COMO INTERFACE EM LC/MS}

A cromatografta gasosa associada à especuromeiria de massa (GC/MS) tcm sido considerada tima técnica amalílica adequada para a análise de misturas complexas. Tem. no enanto, a grande limilação de ser aplicável apenas a moléculas relativamente volálcis c termicamente esláveis. Um acoplamento semelhane entre a cromaımgratia líquida $\mathrm{e}$ a espectrometria de massa (LC/MS) era por isso de lodo o interesse. para a análise de compustos sem aquelas características, para os quais a análiso por GC/MS só podia ser utilizada recorrendo a derivatizaçôes que tornam " processo analítico muito demorado. Uma das mainres diliculdades nesta combinação tem sido a difercuça fundamental entre as condiçōes de operaçăo, sendo de salientar. entre ctas. us lluxos de líquido do LC incompaliveis com o sistema de vácuo do MS da ordem de $10^{-3}$ a
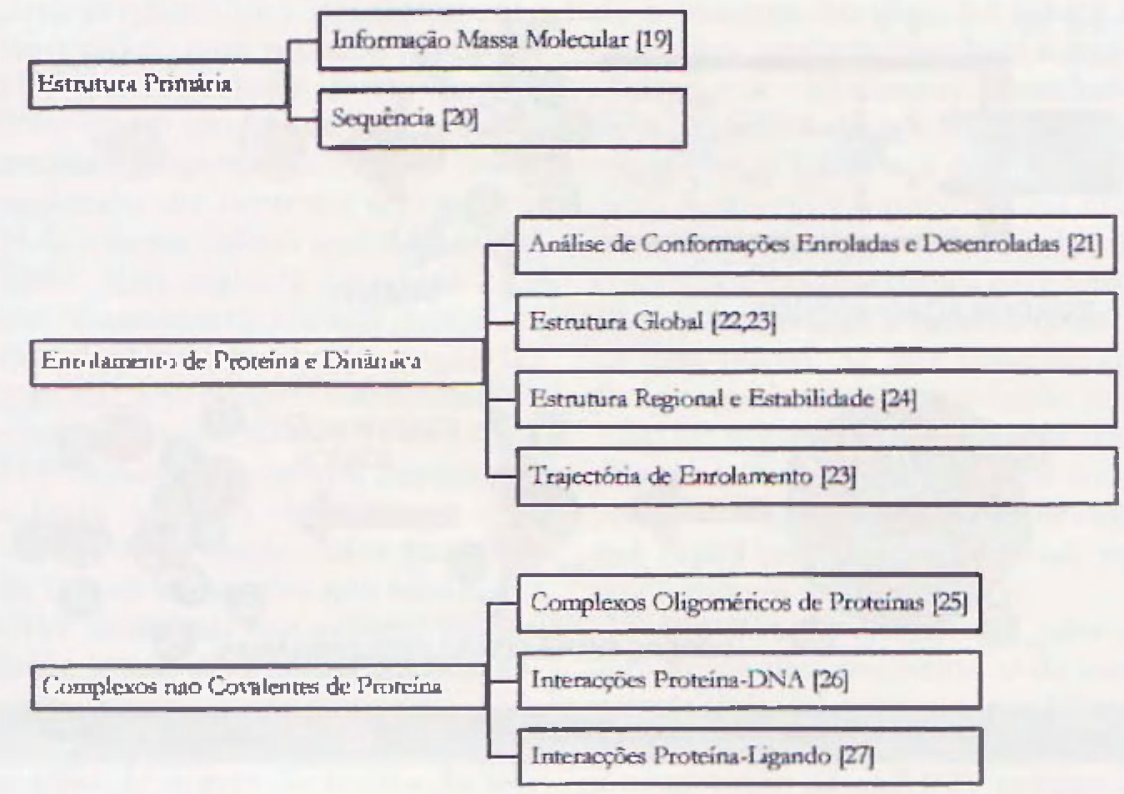

Fig. 3 - Resumo de aplicaçōes de ESI no estudo de proteinas.

10-6 Pa. Várias julcrfaces [7] tên sido desenvolvidas stondo que a interfacc à pressāo atmostérica (API) quarido operada no modo electrospray é únca no sel grande putcrial para a análisc de uma variedade de moléculas com Lma vasta gama de massas moleculares, com uma sensihilidade da ordam dos fentomole. A ionizaçăo por elecurospray requer um fornecimento constante de líquido e é por isso fácilmente acoplada a แח sistema de separação. tal como แm cromatógralı líquido. Uma fonte de electrospray Junciona. portanto. como interface para LCMS. Sāo no entanı vários us parâtmetros que alectam a estabilidade do spray. tais como lensàn superlicial. constante dieléctrica, viscusictade, condulividade e velucidade dic lluxo do solvente. Conseguem-se, no entanto, condiçŏes estávets do spray com uma gana grande de solventes principalmenle com misturas a com velocidades de lluxo da ordem de $1-10,1 /$ min. As velocitlates de Thxo dos efluentes na cromatogralia liquida ( LC ) sầ maiores, variando de - $1 \mathrm{ml} / \mathrm{min}$ para coluñs de empacotamento até $-50 \mu / / m m$ para columas "microborc", velocidades de fluxo demasiado elevadas para utilizar em electrospray convoncional. Para obviar a essa difurença na velucidade dos fluxos foran desenvolvidos diferemtes tipos de interlaces de ES [15]. como sejam o ES assistido preumaticamente [15] to o ES assistido nltrasonicamente [16].

Com o descruvolvimentu a nivel instrumental, L.C-MS tornou-se numa técnica qua poice ser apticada num grande numero de áreas, como por exemplo ambiente [17/ e bioanálisc: $[18]$.

\section{APLICAÇŌES}

A ESIMS sufrú um rápidu crescimento tornando-se numa técnica analíica fundamental para análise de una vasta gama de compostos polares, não voláteis e lermicamentc instáveis, indo de compostos de baixa massa molecular até biopolímeros de elevada massa molecular. Os melhores resuluatos analíticos são. em geral, ohtictos para analitos qu ve sãa iónicos em solução e é dc acreditar que us ióes ohservadus na tase gasusa săo peto menos um rcllcxo qualitarivo dos iòes na soluçào amosira original, retendo asjectos da 
รแล estrutura t associações nào covalentes. O naior sucesso da técnica rem sido na sua aplicaçāo na análisc de moléculas biológicas não voláteis. En princípio todas as moléculas que prodem ser carregadas sāo accssiveis a unla análise por ESIMS. Entre estas encontram-se os peptidos e protuinas que podem ser protonados principalmentc nas zonas básicas, cul scia nos grupos terminais amino. Os aligomucleotidos podem ser carregados no modo iónico negativo: neste caso o grupo foslato lornece a carga por absiracção do protão. Moléculas ncutras, tais como oilgossacaridos. podem também ser dercoradas porque se podem ligar a iōes $\mathrm{Na}^{+}$ou outros melais alcalinos como agente de carregamento.

\section{I. Macromoléculas Biológicas}

A técnica de ESIMS rem sido aplicada em estudos de proceinas quer a nível de estrutura primária, quer secundária. terciária c' quaternária como se pode ver nu resumo apresentado na Fig.3. No que respeila a estrutura primária a técnica hermile não só a determinação da massa molccular como tambúm a deturminação da sequência dos péptidos na molécula. Far-se-á referência à aplicação de ESIMS a esta estruiura, uma vez ģue a ap̣licaçào às vutras estruturas sai fora do ảmbito deste texıo de divulgação.

\section{Determinação de massas moleculares}

Biomoléculas de grandes di. mensōes examinadas por ESIMS apresentam uma distribuiçăo dc molículas multiplamente carregadas t cur gcral nenhuma ocorréncia de Iragmentação. a menos que a dissocjaçăo scja induzida durante o transporce para o espectróntetro dc massa por intermédio de colisōcss.

Para a determinação da massa molecular de uma macrumolécula podem ser usados dois algoritmos |28| en que un deles a designado por algoritno da média. Nésic caso considera-se una molécula multiplamentc carregada dando no espectro de massa um dado valor de $m / z$ que

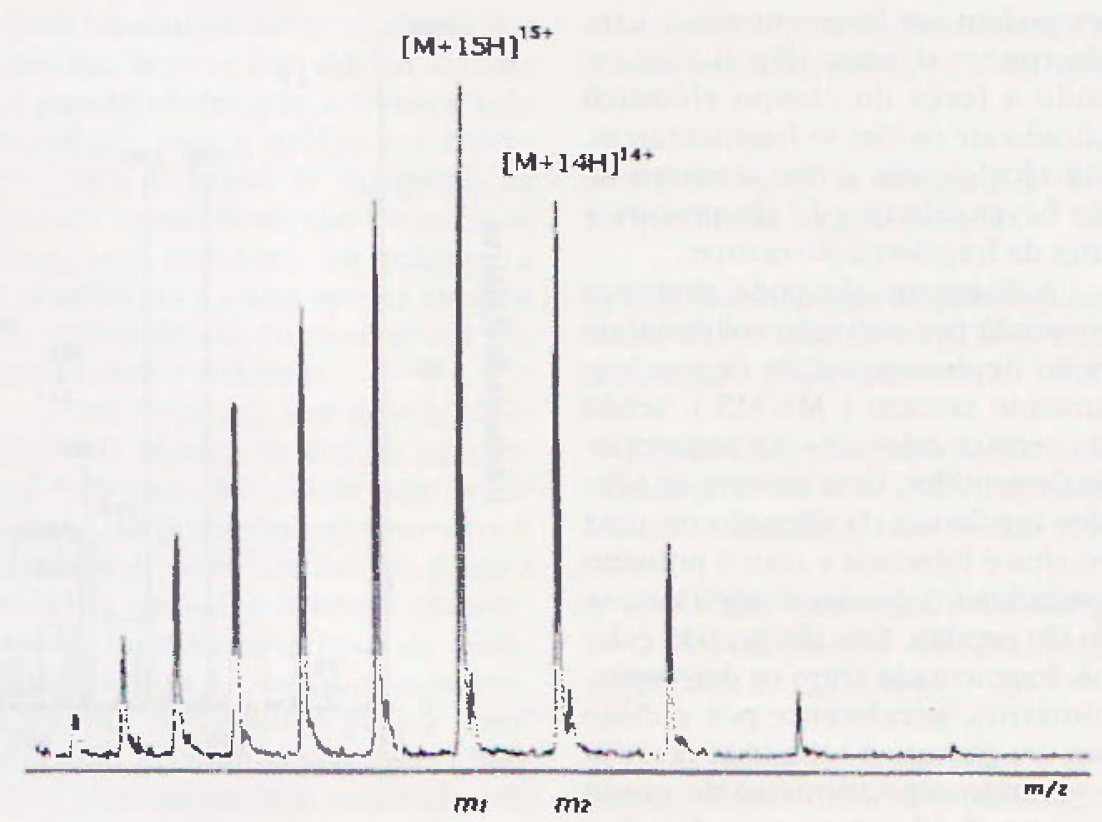

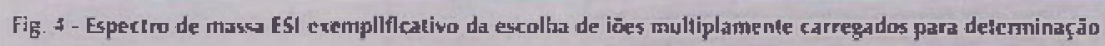
de $\mathrm{M}_{\mathbf{r}}$

se vai designar por $\mathrm{ml}_{\text {l }}$ con carga $\mathrm{z}_{1}$ a masca molecular rulativa $\mathrm{M}_{\text {. }}$ e no caso de se tratar de uma proteina considera-se que a sspucicic que transporta a carga, $\mathrm{M}_{a}$ é um protāo i $\mathrm{M}_{\mathrm{a}}=1,0079$ )

$m_{1} z_{1}=M_{r}+M_{a} z_{1}=M_{1}+1.0079 M_{I}$

Se se considera um outro iāo multiplamentc carregado a $\mathrm{m} / \mathrm{z} \mathrm{m}_{2}$ $\left(\mathrm{m}_{2}>\mathrm{m}_{1}\right)$ (Fig.4) qué está alastado de $m_{1}$ de j picos $(j=1$ para dois picos consccutivos) tent-se

$m_{2}\left(z_{1}-j\right)=M_{1}+1.0079\left(2_{1} \cdot j\right)$

Estas duas equaçōes podem ser resolvidas dando origem às equações ( 3 ) c (4) que permitem calcular o estado de carga e massa molccular da macromolécula

$\mathrm{z}_{1}=\mathrm{j}\left(\mathrm{m}_{2}+1.0079 /\left(\mathrm{ml}_{2}-\mathrm{mm}_{1}\right)\right.$

$M_{\mathrm{T}}=-\mathrm{z}_{\mathrm{E}}\left(\mathrm{m}_{\mathrm{l}}-1.0079\right)$

Se o cálculu for luito para sucessivos partes de jōes adjaccontes obtem-se por último un valor médio para $M_{\Gamma}$.
A desconvolução é outro mudo de extrair iııromaçào do espectro, па qual uma scuuência de picos é transformada rum único pico carregado. Iucalizado numa escala de m/z à massa molecular relativa $M_{r}$ do comnosto. Na prática é utilizado um alguritmo de dusconvoluçāo [28] em quc o cálculo é excoutado pelo sistema de dados do especirometro de massa.

\section{Determinação estrutural}

A. p principais características dos espectros de massa de bionoléculas sāo a predouñañncia de iōes moleculares multiplanente carregados c* a ausência de fragmentação o quc permite a determinação rigorosa de massas moleculartes. No ṫntanto. no que respeica a estrutura molecular pouca inlormaçäo é. ent geral, obtida.

Para sc olyter informaçāo esırutural lá́ quc proceder à fragmentação dos jờs's multiplamence carregados ou na ESI, vu na regiāo de colisão de um instrumento tandem ou ainda numa armadilha iónica.

Embora ES possa ser considera. do uma [onte de ionizaçào suave. us 
iōes podem ser fragmenlados na régiāo conc - skimmer (Fig.2) aumentando a força do campo cléctrico aplicado até os in̉es se fragnentarem. Esta técnica tem a desvantagen de não haver selecçãu do ião precursor antes da fragncintaçào ocorrer.

A Iragmentaçāo podc ainda ser provocada por activaçăo colisional na regiāo de decomposição de um ins. irumento tanden ( MS/MS ), sendo esta técnica relevante na sequenciação de peptidos. Una mistura de peptidos resultante da digestão de uma proteína é injectada e com o primejo espectrómetro de massa selecciona-se un ião peptido. Estc iāo peptido e $\mathrm{dc}$ pois fragmentado entre os dois especirómetros, guralmente por colisāo сюп ил gás raro a uma certa pressão. O segundo espectrómelro de massa separa c mede as massas dos iones Iragmento ptoduzidos pelo ião peptido. Como a fragmentação ocorre pre. ferencialmentc nas ligaçōes amida. o espectro consiste numa séric de picos dilerindo nas massas dos resíduos dos aminoácidus.

Por último a โragnentacão pode ter origem na aciivação colisional, que ocorre em instrumentos que disponham de uma armadilha iónica ou em instrumentos de ressanáncia ciclotrónica de jōes. o que também permite a realização de cxperièncias de MS/MS.

\subsection{Ambiente}

A lécnica de jonizaçāo por elcctrospray năo é só importante para o estudo de macromoléculas. como também é de reconhecido interesse para a resolução de problemas añbientais em que os contaminantes กão são, en geral, conslituídos por moléculas de grandes dimensōes.

Un exemplo de problema ambiental envolve a especiaçäo de compostos organometálicos e inorgânicos de cslasho e arsénio porquc o potencial bixico destes compostos cstá forlemente dependente da sua especiação química e do processamento hiogcoquimico pelos ecossistcmas.

No respcilante aos compostos alquilo e arilo estànicos, alıamente
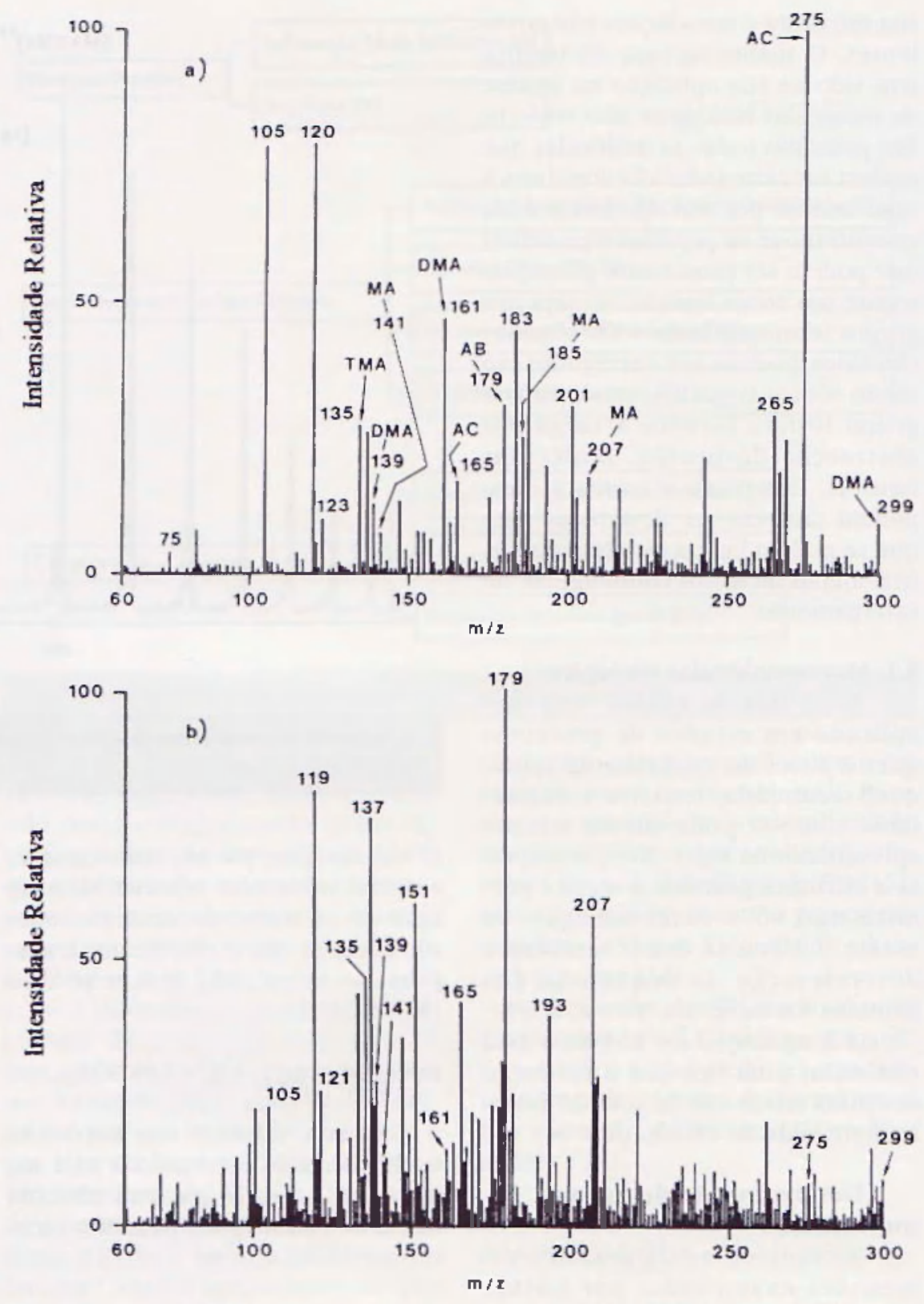

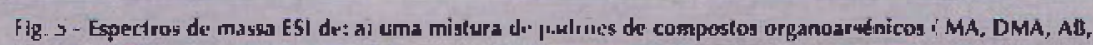
AC, TMA i; b) um extracto de ỉgwa do estuario do Tejo.

tóxicos, eles foram estudados por ESIMS acoplada à LC [29]. sol, condiçōes de ionizaçăo posilliva $e^{\prime}$ os rcsultados olıidos levaram a considerar que a técnica tenn o potencial para se tortiar uma ferramenta importante para monilurar e medir estc tipo de composios no ambicntc.

Quanto aos composios de arsénjo, quantidades elevadas de arsénio เĉm sido medidas nas águas do estuário do Tejo |30) resultantes em parte da lundiçāo de pirites. Particulamente impurtantes parecem ser as formas de arsc̆mio que não formam hidre:os a $1 \mathrm{~cm}$ sido designadas de "refractárias" ou "ocultas" [31] e que constituem cerca de 50\% do As nas águas do estuários.

$\hat{F}$ de todo o interesse o deseñ. volvimento de lécnicas analíticas con. 
vententes para a identificação e quantificaçāo destas espécies no ambiente. Un certo número de dificuldades surgem, no entanto, devido aos baixus niveis em que estas formas ucorrem associadas aos efeitos da tmatıi\% (onplexa da água do es-tuário. Foi possível identificar, por ESIMS (Fig.5). uma série de compostos contendo arsénio nas águas do esıário do Tejo por comparaçāo com un espectro de massa ESI de uma mistura de padrōes, arsenobetaína, AB, arsenocolina. AC. ácido metàlarsunico, MA. ácido dinetilarsínico. DMA, e ião te:rantelila rsónio. TMA [32].

Recorrendo a папoelectrospray, [oram também identificados arsenoaçúcares [33]. no modo neģativo o que permitiu serem detectados ao nível do picograma. tendo sido ainda identificado ঘm arsenoaçúcar num extracto de uma alga.

Muitos outros problemas ambientals poderảo ser resolvidos recorrendo a ESI quer acoplado a LC ou não. Um exemplo do $\mathrm{J}^{\text {" caso foi a }}$ sula aplicação à quuanıificação de herbicidas imidazulinona cm amostras de solos e águas naturais. Embora tenham sido usadas duas técnicas. LC/UV e LC/ESIMS, no caso dos solos, dada a complexidade da matriz. e as concentraçöes vestigiais da ordem de fracçö́s do ng/g de solo, as análises foram apenas cicctuadas por LCIESIMS pot ser uma técnica mais sensivel e específica do que LC/UV [34]. Recentemente foi publicado um arligo [35] em que a técnica ESI/MS, dado o baixo limite de deteç̧òo. foi considerada uma técnica a ier em conta para, associada con resultados obtidos por outras técnicas, aumentar a confiang no rigor das determinaçóes de perclorato. cuntaminantc ambicntal de áyuas da rede de consumo, que faz parte da Lista de Candidatos de Contaminan1es de Água de Beber da Agência dc Prosecção Ambiental dos EUA.

\section{CONCLUSÓES E PERSPECTIVAS}

O enorme sucesso da técnica de ESIMS que se desenvolveu a um ritmo espantoso desde os linais dos anos 80. deve-se sem dívida alguma às possibilidades que a lécnica veio introduzir para a anălise por espectrometria de massa de compostos de elevada massa tnolccular de todos os lipos, sem esquecer. no entanto, a sua aplicação a outro tipo de analitos de importância funciamçntal em áreas como $v$ ambiente.

Esta técnica é, scon dúvida alguma, uma técnica de clẹiçăo para es tudos de protcínas e ioda tima investigaçào de problemas que envolvem este tipo de biomoléculas tais como a maneira como se dobram. interacıuan com diferentes tipos de moléculas e levam a cabo tunçóes específicas que contribuem para a conjpreensão de muitus processns biológicos. Outras técnicas analíticas nảo podem fornecer o nusmo nivel de informaçāo détaltada no respeitante a massas moleculares e estruturas a partir de quantidades extrenamentc pequenas de amostras.

É de crer que, polo menos nos próximos anos, esta técnica que alingiu já clevados níveis dé sensibilidade e de cspecificidade continuará a ser de importância fundamental para a espectrometria de massa analítica con desenvolvimenuss futuros princtpalmente na área de acoplamento a técnicas de sẹparação.

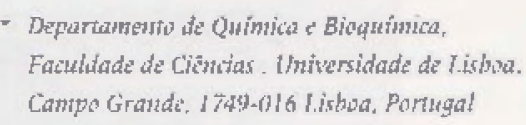

\section{REFERÊNCIAS}

1. M. Dole, L. L. Mack, R. L. Hines, R. C. Mobley, L. D. Ferguson e M. B. Alice, I. Chem. Phys. 49. 2240 (1968).

2. M. Yamastila e J. B. Fenn, J. Phys. Chem. , 88, 4451 (1984).

3. J. V. Iribarne e B. A. Thomson, A. Chem. Phys. . 64. 2287 (1976).
4. L. Esteban, La Espectronetría de Masas en imagenes. ACK Editores [1993\}.

5. S. F. Wons, C. K. Meng e J. B. Fenm, 1. Pinys. Chem. 92, 546 (1988).

6. R. B. Cole (Eclitur), Electrospray Ionzation Mass Spcctrometry, John Wiley \& Suns Inc. . Chichester (1997).

7. Liquid Chronatography-Mass Spectrometry, 2" Ed. , W. M. A. Niessen. Marcei Dekker Inc. . New York (1999).

8. R. B. Cody, I. Tanura, J. W. Finch c B. D. Musselman, J. Am. Soc. Mass Spectrom. 5. 194 (1994).

9. C. K. Meng, C. N. McEwen e B. 5. Larsen, Ripid Commun. Mass Spectrom1. 4, 147 (1990).

10. R. T. Galataher, J. R. Chapman e M. Mann. Rajpid Coninum. Mass Spectrom. , 4, 369 (7990).

11. K. D. Henry, Org. Mass Spectrom. , $25,490(1990)$.

12. E. R. Williams, Anal. Chem. News \& Features, March 1. J79A 11998).

13. I. G. Boyle e C. M. Whitehouse, Anal. Chem. , 64, 2084 (1992).

14. I. V. Chermishevirh, W. Enș e K. G. Standing. Anal. Chent. News \& Features, $452 \mathrm{~A}$. July (1999).

15. A. P. Bruins, T. R. Covey e J. D. H. Henion, Anal. Chem. , 59. 2642 (1987).

16. A. Hirabayashi, M. Sakairi e $H$. Koizumi, Anal. Chem. 66, 4557 (1994).

17. J. Slohodnik. B. L. M. van Baare U. A. Th. Brinkman, J. Chromatogr. A. $703.81(1985)$

78. E. Gelpi. 1. Chromatogr. A, 703, 59 (1995).

19. R. Feng e Y. Konishi, Anal. Chem., 64. 2090 (1992). 
20. A. Shevchenko, 1. Chernushevich. W. Ens, K, G. Standing, B. Thumson. M. Wilm e M. Mann, Rapid Commun. Mass Spectrom. 11, 10J5 (7997).

21. V. Katta e B. T. Chait, J. Am. Chem. Soc. , 113, 8534 (1991).

22. V. Katta e B. T. Chait, I. Am. Chem. Soc., 115, 6317 (1993).

23. A. Miranker, C, V. Robinson, S, E. Racliord. R. T. Aplin e C. M. Dobson, Science, 262, 896119931.

24. D. L. Smith, Y. Deng e Z, Zhang, J. Mass Specirom. , 32, 135 \{1997).

25. B. L. Schwartz, J. E. Bruce, G. A. Anderson. S. A Hofstadler. A. L. Rockwood, R. D. Smith, A. Chilkoti e P. S. Stayton, J. An. Soc. Mass Spec- trom. . 6. 459 (995).

26. X. Cheng, P. E. Morin, A. C. Harms, J. E. Bruce, Y. Ben-David E R. D. Smith, Anal. Biochem. 239. 35 (1996).

27. M. Ishigai, J. I, Langridge, R. S. Bordoli e S. J. Gaskell, J. An. Soc. Mass Specirom. , 11, 606 (2000).

28. 28. M. Mann, C. K. Meng e J. B. Fenn, Anal. Chem. 61, 1702 (1989).

29. T. L. Jones e L. D. Betowski, Rapid Commun. Mass Spectrom. „7. 1003 (1993).

30. A. M. deBettencourt, M. H. Florêncjo, M. F. N. Duarte, M. L. R. Gomes e L. F. C. Vilas Boas, Appl. Organometal. Chem. 8. 45 (1994)
31. A. G. Howard e S. W. D. Comber, Appl. Organometal. Chom. 3. 509 (1989).

32. M. H. Florêncio, M. F. Duarte, S. Facchetti, M. L. Gomes, W. Goessler. K. J. Irgolic, H. A. van'I Klooster, L. Montanarella. R. Ritsema, L. F. VilasBoas e A. M. M. de Bettencourt, Analusis, 25. 226 ( 7997 ).

33. S. A. Pergantis, 5. Wangkarn, K. A. Francesconi e I. E. Thomas-Oates, Anal. Chen. .

72. 357 (2000).

34. A. Laganà, G. Fago e A. Marino, Anat Chem. , 70, 121 (1998).

35. M. L. Magnuson, E. T. Urbansky e C. A. Ketty, Anal. Chem, 72, 25 $\{2000)$.

\section{APCER \\ Cerifiado de Comomilade in:

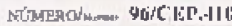

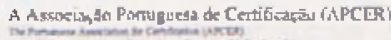

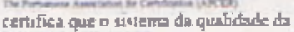

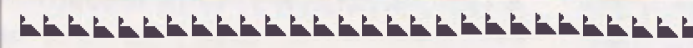

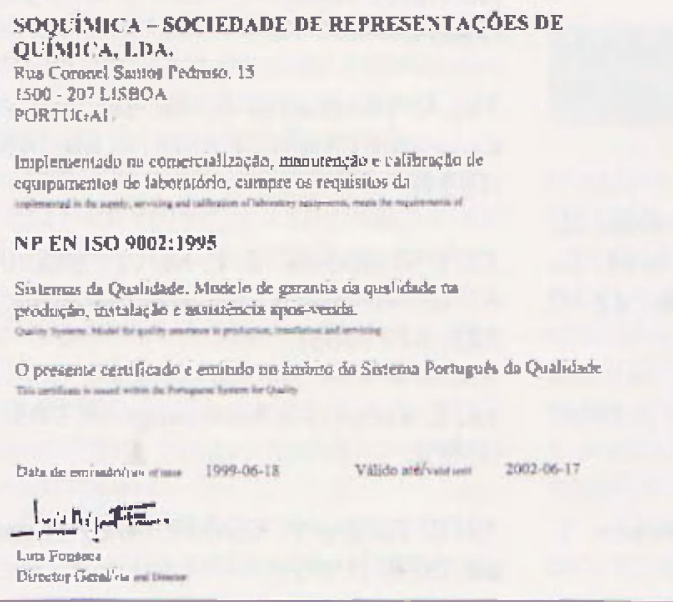

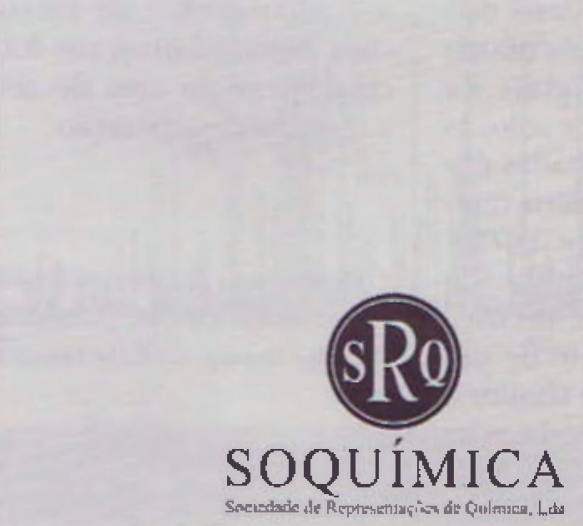

R. Coronel Santos Pedrosa 15 - 1500-207 Lisboa Tel 21 716 5160 - Fax 217165169 R. 5 de Qutubro 269 . 4100 -175 Porto Tel 226093069 . Fax 226000834 E-mail: soqumima(@mail, relepac pt.
wWw.suquimica.pt 